\section{ONE COMMITTEE MORE}

THE decision of the British Government to establish yet another committee for the co-ordination of research is a surprise but not necessarily a mistake. If the object is to provide better co-ordination, and if the committee under Sir Solly Zuckerman can do just that, everybody will benefit. Certainly there has been plenty of evidence in the past two years of inadequate liaison between the ministries responsible directly or indirectly for the strategy of scientific research. The gulf between the Ministry of Technology and the Department of Education and Science which followed the reconstruction of these departments in 1964-and which more recently has become less conspicuous-was a needless impediment to easy planning for which the Government itself was chiefly responsible. The gulf between the departments responsible for civil and defence research raises bigger problems, not the least of which is that of constructing sets of criteria with which to make decisions about the long-term benefits of committing resources to work in two such different fields. It follows that if the Zuckerman Committee is to make sense at all, it must be free to cover all the ground.

But is co-ordination and the knocking together of heads the sole objective? Everything will turn on the relationship there is to be between the new committee and the committces which at present advise the separate departments of government on scientific policy. The Council for Scientific Policy is particularly important, for it has been thought of as the residuary legatee of the old Advisory Council on Scientific Policy. Its own interpretation of its terms of reference has gone beyond the category of "pure research" which the Prime Minister used on October 25, and it is not so long since the freedom of the council to consider broad questions not necessarily arising from the affairs of the research councils was being offered as a proof that the Government's administration of scientific policy is not as fragmented as it seems to be on paper. What has now gone wrong? Has the Government found unpalatable the advice it has been getting, or is it seeking some way of forcing through more radical changes than the existing committees would recommend? Is it, for example, seeking a drastic shift in the balance between academic and applied research ? To mention these suspicions is not to suggest that they must have substance, but merely that the Government still has a lot of explanation to do before it can hope to convince the scientific community that it is embarking on wise policies.

The issue at stake is one of public confidence. Haphazard though it may have been, the design of scientific strategy in recent years has given working scientists at least an illusion that they could participate in making policy. For one thing, members of committees such as the Council for Scientific Policy, although often deeply engaged in some other activity, are usually accessible. Then their reports are published and are widely read and argued. One important result has been an awareness among scientists of the problems of allocating resources. In the long run a responsible recognition by the community most directly concerned could do more to simplify the administration of science than a hundred advisory committees, however wise. On the face of things there is a danger that the new committee, though more powerful and probably more efficient, may be less well placed to carry with it the community of scientists and technologists. The presence of the Royal Society on the proposed cor. mittee will only be a partial safeguard. It will take time for the Royal Society to learn how best to use its influence in public affairs-which is no reason for thinking that it should not make the effort. (Presumably the Prime Minister has not forgotten the engineers, though there is no mention of them in his statement.) In the meantime, there can be no real substitute for a full declaration by the Government of what it has in mind. The problem is not merely to persuade reluctant scientists that their affairs are being managed properly, but also most effectively to harness their willingness to help in deciding what must be done.

That said, there is a great deal that the committee could accomplish. The most obvious task ahead of it is to find some way of stimulating the better use of science and technology in British industry. This is not just a matter of exhortation. Methods must be found of persuading industry that scientists and technologists can earn their keep, for in the long run this is the only way of tempting them away from academic life and from other occupations which contribute less productively than they might to the British economy. As it happens there is a great deal to be done within the working of the Government itself. Thus the Zuckerman Committee could well begin by tackling some of the impediments to the movement of skilled labour within the Government and between the Government and the outside world. Tangible and humdrum matters such as pensions rights are often most powerful means of keeping people working at the wrong jobs, and government pensions are often the most immobilizing. Then the Government could do much to change the attractiveness of scientific careers by improving the practice of its own industrial establishments. But these are only palliatives. The more urgent need is to encourage a more imaginative view - not merely among industrialists but also among technologists themselves-of what might be done in industry. If the Zuckerman Committee can help the Ministry of Technology to tackle these problems more effectively, that will be an important gain.

The other field that cries out for attention is defence. The coming dismemberment of the Ministry of Aviation is a splendid opportunity for making sense of the present practices in military research and development. The better use of existing resources, either by avoiding duplication or by seeing that people are more effectively employed, is an obvious and immediate goal. But it is equally important to create machinery to help in making more accurate decisions in military research. 